\title{
Everolimus With Very Low-Exposure Cyclosporine A in De Novo Kidney Transplantation: A Multicenter, Randomized, Controlled Trial
}

\author{
Maurizio Salvadori, ${ }^{1,22}$ Maria Piera Scolari, ${ }^{2}$ Elisabetta Bertoni, ${ }^{1}$ Franco Citterio, ${ }^{3}$ Paolo Rigotti, ${ }^{4}$ \\ Maria Cossu, ${ }^{5}$ Antonio Dal Canton, ${ }^{6}$ Giuseppe Tisone, ${ }^{7}$ Alberto Albertazzi, ${ }^{8}$ Francesco Pisani, ${ }^{9}$ \\ Giampiero Gubbiotti, ${ }^{10}$ Gianbenedetto Piredda, ${ }^{11}$ Ghil Busnach, ${ }^{12}$ Vito Sparacino, ${ }^{13}$ Volker Goepel, ${ }^{14}$ \\ Piergiorgio Messa, ${ }^{15}$ Pasquale Berloco, ${ }^{16}$ Domenico Montanaro, ${ }^{17}$ Pierfrancesco Veroux, ${ }^{18}$ \\ Stefano Federico, ${ }^{19}$ Marta Bartezaghi, ${ }^{20}$ Giuseppe Corbetta, ${ }^{20}$ and Claudio Ponticelli ${ }^{21}$
}

\begin{abstract}
Background. In combination with everolimus (EVL), cyclosporine A (CsA) may be used at low exposure, so reducing the risk of renal dysfunction in renal transplant recipients (RTR). We evaluated whether higher exposure of EVL could allow a further reduction of CsA.

Methods. De novo RTR were randomized to standard exposure EVL (C0 3-8 ng/mL) with low-concentration CsA (C2 maintenance levels 350-500 ng/mL, group A) or higher EVL exposure (C0 8-12 ng/mL) with very low-concentration CsA (C2 maintenance levels 150-300 ng/mL, group B). The primary endpoints were 6-month creatinine clearance $(\mathrm{CrCl})$ and biopsy-proven acute rejection (BPAR) rate. After 6 months, patients were followed up (observational extension) to 12 months.

Results. Two hundred eighty-five RTR ( $97 \%$ from deceased donors) were enrolled. Two patients per group died (1.4\%). The 6-month death-censored graft survival was $90.2 \%$ in group A and $97.9 \%$ in group B and was unchanged at 12 months $(P=0.007)$. There was no significant difference between groups at 6 months in $\mathrm{CrCl}(59.9$ vs. $57.8 \mathrm{~mL} / \mathrm{min})$ and BPAR rates $(14.7 \%$ vs. $11.9 \%)$ and also at 12 months $(\mathrm{CrCl} 62.5 \pm 20.7$ vs. $61.3 \pm 22.0 \mathrm{~mL} / \mathrm{min}$, BPAR $14.7 \%$ vs. $14.1 \%)$. No significant differences were seen in treated acute rejections, steroid-resistant acute rejections, treatment failures, or delayed graft function, although there was a trend to better results in group B.

Conclusions. EVL given at higher exposure for 6 months plus very low CsA concentration may obtain low acute rejection rate and good graft survival in De novo renal transplantation. However, there was no difference between groups in $\mathrm{CrCl}$.
\end{abstract}

Keywords: Kidney transplantation, Immunosuppression, Randomized clinical trial.

(Transplantation 2009;88: 1194-1202)

$\mathrm{E}$ verolimus is a macrolide lactone with proliferation signal inhibitor activity. Because of the introduction of a 2-hydroxyethil group in position 40 (1), it differentiates

This work was supported by Novartis Farma SpA, Italy.

C. Ponticelli is a consultant of Novartis, Italy; G. Corbetta and M. Bartezaghi are full-time employees of Novartis Farma SpA, Italy.

M. Salvadori contributed to protocol writing, patient recruitment and followup, data collection, and manuscript revision; C. Ponticelli, M. Bartezaghi, and G. Corbetta contributed to protocol writing, analysis of data, and manuscript writing; M.P. Scolari, F. Citterio, P. Rigotti, V. Sparacino, P. Berloco, D. Montanaro, P. Messa, and S. Federico contributed to study protocol concept, patient recruitment and follow-up, data collection, and manuscript revision; V. Goepel, P.F. Veroux, E. Bertoni, M. Cossu, A. Dal Canton, G. Tisone, A. Albertazzi, F. Pisani, G. Gubbiotti, G.B. Piredda, and G. Busnach contributed to patient recruitment and follow-up, data collection, and manuscript revision.

${ }^{1}$ Renal Transplant Unit, Careggi University Hospital, Florence, Italy.

${ }^{2}$ Renal Transplant Unit, S. Orsola Malpighi University Hospital, Bologna, Italy.

${ }^{3}$ Department of Surgery, Catholic University Hospital, Rome, Italy.

${ }^{4}$ Surgery Division, Policlinico University Hospital, Padua, Italy.

${ }^{5}$ Renal Transplant Unit, SS. Annunziata Hospital, Sassari, Italy.

${ }^{6}$ Renal transplant Unit, IRCCS S. Matteo University Hospital, Pavia, Italy.

${ }^{7}$ Division of Surgery and Renal Transplant Unit, S. Eugenio University Hospital, Rome, Italy. from sirolimus for a shorter half-life. In a randomized controlled trial (RCT), everolimus (EVL) was not inferior to mycophenolate mofetil in preventing acute rejection (AR) when both drugs were given in combination with standard doses of cyclosporine A (CsA) (2). However, the mean creatinine

\footnotetext{
${ }^{8}$ Renal Transplant Unit, Policlinico University Hospital, Modena, Italy.

${ }^{9}$ Renal Transplant Unit, Civile S. Salvatore Hospital, L'Aquila, Italy.

${ }^{10}$ Renal Transplant Unit, S. Maria della Misericordia Hospital, Perugia, Italy.

${ }^{11}$ Renal Transplant Unit, G. Brotzu Hospital, Cagliari, Italy.

${ }^{12}$ Renal Transplant Unit, Niguarda Cà Granda Hospital, Milan, Italy.

${ }^{13}$ Renal Transplant Unit, Civico e Benfratelli Hospital, Palermo, Italy.

${ }^{14}$ Renal Transplant Unit, S. Bortolo Hospital, Vicenza, Italy.

${ }^{15}$ Nephrology and Renal Transplant Unit, IRCCS De Marchi and Policlinico Foundation, Milan, Italy.

${ }^{16}$ Clinica Chirurgica II, Umberto I University Hospital, Rome, Italy.

${ }^{17}$ Renal Transplant Unit, S. Maria della Misericordia University Hospital, Udine, Italy.

${ }^{18}$ Vascular Surgery and Transplant Unit, Policlinico Hospital, Catania, Italy.

${ }^{19}$ Renal Transplant Unit, University Hospital “Federico II,” Naples, Italy.

${ }^{20}$ Medical Department, Novartis Farma SpA, Origgio, Varese, Italy.

${ }^{21}$ Division of Nephrology, Istituto Scientifico Humanitas, Milano, Italy.

${ }^{22}$ Address correspondence to: Maurizio Salvadori, M.D., SOD Nefrologia dei Trapianti e Dialisi, Azienda Ospedaliera Careggi, Viale Gaetano Pieraccini 17, 50139 Florence, Italy.
} 
clearance $(\mathrm{CrCl})$ levels were lower in patients assigned to EVL when compared with those assigned to mycophenolate mofetil. Further studies showed that the risk of AR was related to low EVL blood levels rather than to CsA blood levels (3), suggesting that CsA dose could be reduced, when given in association with EVL, without compromising efficacy. In another $\mathrm{RCT}$, renal transplant recipients given basiliximab, corticosteroids, and EVL ( $3 \mathrm{mg} /$ day) were assigned to reduced-dose CsA (C0 levels between 50 and $100 \mathrm{ng} / \mathrm{mL}$ ) or standard dose CsA (C0 levels between 150 and $250 \mathrm{ng} / \mathrm{mL}$ ). After 3 years, the efficacy failure (AR, graft loss, death, and lost to follow-up) was significantly lower in patients receiving reduced-dose CsA (4). Two other multicenter trials confirmed excellent 1-year graft survival and good renal function in renal transplant patients assigned to receive 1.5 or $3 \mathrm{mg}$ /day of EVL in combination with reduced-dose CsA (5).

This RCT evaluated possible differences on safety and efficacy between two regimens based on the EVL-CsA association. De novo renal transplant recipients were randomized to receive EVL at a dose targeted to maintain blood levels (C0) between 3 and $8 \mathrm{ng} / \mathrm{mL}$ and reduced-dose CsA or to receive higher doses of EVL (C0 8-12 ng/mL) in combination with very low CsA doses.

\section{MATERIALS AND METHODS}

\section{Study Design and Patient Population}

This 6-month, prospective, open-label parallel group RCT with 12-month follow-up enrolled recipients (18 to 65 years) of single kidney transplant from a deceased or nonhuman leukocyte antigen (HLA) identical living donor, aged 14 to 65 years. The study protocol was approved by ethical committees at each participating institution. The study was conducted in compliance with the provisions of the Declaration of Helsinki and Good Clinical Practice guidelines, and all patients gave informed consent in written form to study participation. Exclusion criteria were pregnancy, a current panel reactive antibody titer more than or equal to $50 \%$, a previous transplant failed within 1 year, diagnosis of focal segmental glomerulosclerosis or primary hyperoxaluria, chronic active hepatitis, HIV positivity, plasma cholesterol levels more than or equal to $350 \mathrm{mg} / \mathrm{dL}$ ( $\geq 9.1 \mathrm{mmol} / \mathrm{dL})$, or triglyceride levels $\geq 500 \mathrm{mg} / \mathrm{dL}$ ( $\geq 5.6 \mathrm{mmol} / \mathrm{L})$.

Within $24 \mathrm{hr}$ from graft reperfusion, patients were randomized 1:1 to the following groups:

\section{Group A: Standard EVL+Low-Exposure Neoral}

The starting dose of EVL (Novartis Ag, Basel, Switzerland) was $0.75 \mathrm{mg}$ twice daily (b.i.d.), then adjusted to reach and maintain a blood level of 3 to $8 \mathrm{ng} / \mathrm{mL}$ until the end of month 6. The initial dose of Neoral (CsA for microemulsion; Novartis Ag, Basel, Switzerland) was $2 \mathrm{mg} / \mathrm{kg}$ b.i.d., adjusted to reach a target blood level (C2) of 500 to $700 \mathrm{ng} / \mathrm{mL}$ within day 5 and to maintain the same level until the end of month 2,

E-mail: salvadorim@aou-careggi.toscana.it

Received 27 April 2009. Revision requested 26 May 2009.

Accepted 23 July 2009.

Copyright (๑) 2009 by Lippincott Williams \& Wilkins

ISSN 0041-1337/09/8810-1195

DOI: 10.1097/TP.0b013e3181bb43ec then slowly reduced to reach 350 to $500 \mathrm{ng} / \mathrm{mL}$ within month 6. Suggested C2 levels until month 12 were 350 to $450 \mathrm{ng} / \mathrm{mL}$.

\section{Group B: Upper EVL + Very Low-Exposure Neoral}

Upper target EVL+very low-exposure Neoral. As in group A, EVL was started at $0.75 \mathrm{mg}$ b.i.d, and the dose adjusted to reach a blood level of 3 to $8 \mathrm{ng} / \mathrm{mL}$ in the first week. After the first week, the EVL dose was adjusted to reach a C0 of 8 to $12 \mathrm{ng} / \mathrm{mL}$. Neoral starting dose was $2 \mathrm{mg} / \mathrm{kg}$ b.i.d., then adjusted to target a C2 level of 500 to $700 \mathrm{ng} / \mathrm{mL}$ within day 5 and until day 7; after day 8, when the EVL target levels had been reached, the CsA dose was reduced to target a C2 of 250 to $450 \mathrm{ng} / \mathrm{mL}$ by the end of month 2 , then tapered to 200 to 400 by the end of month 4 and 150 to $300 \mathrm{ng} / \mathrm{mL}$ by the end of month 6 . The same blood level had to be maintained until month 12 .

EVL blood levels were monitored at local laboratory using the fluorescence polarization immunoassay kit (Innofluor Certican, Seradyn). All patients received basiliximab (Simulect; Novartis Ag, Basel, Switzerland) $20 \mathrm{mg}$ intravenously on days 0 and 4 after transplantation, intravenous methylprednisolone (500 $\mathrm{mg}$ on day 0 and $40 \mathrm{mg}$ on day 1 ), and oral prednisone (20 $\mathrm{mg} /$ day) in a single morning dose until day 7 , then gradually tapered to a dose of $5 \mathrm{mg} /$ day after day 45 .

Randomization codes were generated at Novartis Farma SpA (Origgio, Varese, Italy), using a validated computer method. Each center was assigned an adequate number of sealed envelops, each of them labeled with a unique patient number, that were opened after transplantation immediately before the administration of the first EVL dose.

The core study lasted 6 months. Patients completing the core study were entered in an observational follow-up and allowed to continue the assigned treatment.

ARs were treated with intravenous methylprednisolone pulses; anti-lymphocyte antibodies were allowed for grade III rejections or steroid-resistant rejections (see definitions). Cytomegalovirus (CMV) prophylaxis was mandatory in CMVnegative recipients with CMV-positive donors. All patients received prophylactic treatment for Pneumocystis carinii pneumonia for 6 months.

\section{Study Assessments}

\section{Efficacy}

The primary outcome measures were the 6-month $\mathrm{CrCl}$ estimated according Cockcroft and Gault (6) and the proportion of patients with biopsy-proven acute rejection (BPAR) in either arm. The graft biopsies were examined locally according to the Banff' 97 criteria (7).

Secondary outcome measures were the proportion of patients with graft loss, death, treated ARs, antibody-treated $\mathrm{AR}$, and the estimated glomerular filtration rate (GFR) according to Nankivell (8). The presence and duration of delayed graft function (DGF), defined as a need for dialysis in the postoperative period, were also recorded.

\section{Risk of BPAR and Blood Levels of Drugs}

The correlation of the EVL and CsA blood levels with the presence of BPAR within the first 3 months after transplantation was investigated. To estimate the effect of the concentration of the drugs on the risk of BPAR, a survival analysis 


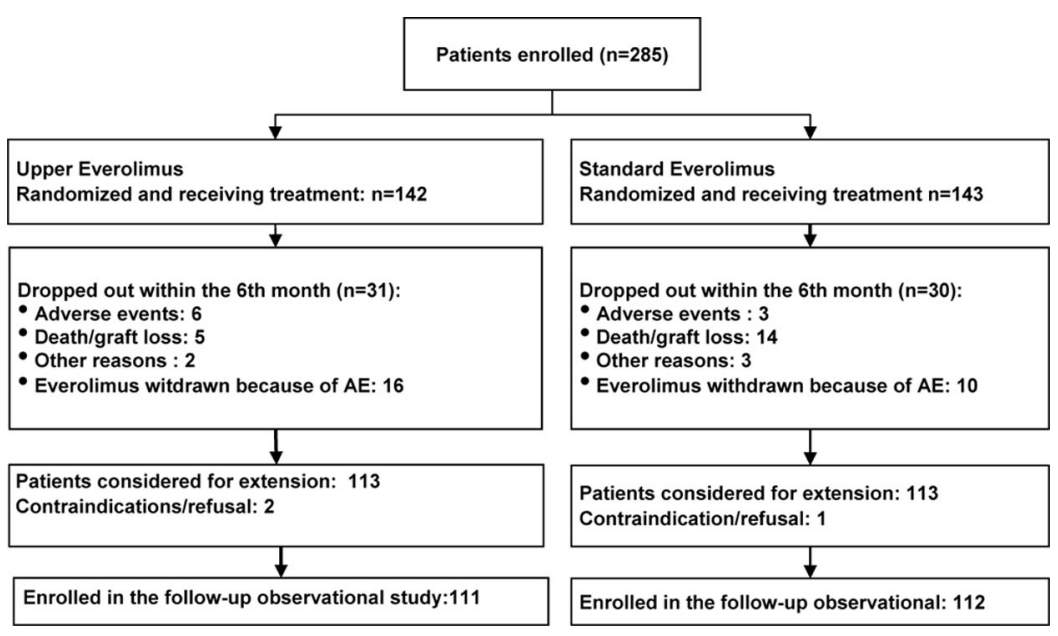

FIGURE 1. Patient disposition.

Post Hoc Analysis

A post hoc analysis was conducted on the treatment compliant population, defined as patients in whom at least $50 \%$ of both CsA and EVL levels from month 2 were within the target blood levels in each group. This analysis was conducted both on the $\mathrm{CrCl}$ (using a LOCF) and on the GFR in patients with functioning graft.

\section{RESULTS}

\section{Patient Characteristics and Demographics}

Between May 2005 and January 2007, 285 patients were enrolled into the study before transplant surgery in 20 centers in Italy. None of the eligible patients was excluded from randomization and subsequent analysis. Only eight patients $(2.8 \%)$ received a kidney from a living donor. Patient disposition is shown in Figure 1. There were no differences between the two groups in the main donor or recipient demographic characteristics (Table 1).

\section{Efficacy}

\section{Primary Endpoints}

The mean 6-month $\mathrm{CrCl}$ in patients with functioning grafts was $59.9 \pm 18.6 \mathrm{~mL} / \mathrm{min}$ in group A and $57.8 \pm 19.3 \mathrm{~mL} /$ min in group B. The difference between groups was not significant, even when the LOCF approach was used $(P=0.7)$. At 12 months, the mean $\mathrm{CrCl}$ was $62.5 \pm 20.7 \mathrm{~mL} / \mathrm{min}$ in group A versus $61.3 \pm 22.0 \mathrm{~mL} / \mathrm{min}$ in group $\mathrm{B}$. In this group, the recovery of $\mathrm{CrCl}$ after transplantation tended to be faster, although the differences with group A were never significant at any time point. The mean GFR values (Nankivell) at 6 and 12 months were, respectively, $62.3 \pm 15.6$ and $64.8 \pm 17.7 \mathrm{~mL} /$ min in group A in comparison with $60.0 \pm 16.4$ and $63.8 \pm 18.3 \mathrm{~mL} / \mathrm{min}$ in group B. $(P=\mathrm{NS}$, Fig. 2$)$.

Within month 6, the BPAR event rate was $14.0 \%$ (20/ 143 ) in group A and $11.3 \%(16 / 142)$ in group B. The upper limit of the $97.5 \%$ confidence interval of the difference was $4.99 \%$ (i.e., $<15 \%$ ), confirming the noninferiority of group B versus group A. Kaplan Meier estimates of BPAR at 6 months are reported in Table 2. Between 6 and 12 months, another patient in group A and four in group B developed a BPAR $(P=\mathrm{NS})$. The cumulative probability of BPAR at 1 year in groups A and B was, respectively, $14.7 \%$ and $14.1 \%$. rank test. 
TABLE 1. Baseline characteristics of study population

\begin{tabular}{cc}
$\begin{array}{c}\text { Standard } \\
\text { everolimus, } \\
\text { group A }\end{array}$ & $\begin{array}{c}\text { Upper } \\
\text { everolimus, } \\
\text { group B }\end{array}$ \\
$(\mathrm{N}=143)$ & $(\mathrm{N}=142)$ \\
\hline
\end{tabular}

Age (yr)

$\begin{array}{lcc}\text { Mean (SD) } & 45.8(10.6) & 45.4(11.7) \\ \text { Range } & 22-66 & 19-65 \\ \text { Male sex (\%) } & 65.7 & 62.7 \\ \text { Previous transplant (\%) } & 10(7.0) & 5(3.5) \\ \text { Hypertension at transplantation (\%) } & 116(81.1) & 126(88.7) \\ \text { Disease leading to TX (\%) } & & \\ \quad \text { Glomerulonephritis } & 56(39.2) & 38(26.8) \\ \text { Interstitial nephritis/pyelonephritis } & 11(7.7) & 13(9.2) \\ \text { Polycystic kidney disease } & 26(18.2) & 23(16.2) \\ \text { Nephrosclerosis } & 8(5.6) & 20(14.1) \\ \text { Urinary obstruction/vesicoureteral } & 3(2.1) & 9(6.3) \\ \quad \text { reflux } & & \\ \text { Other/unknown } & 39(27.3) & 39(27.5) \\ \text { Donor age, yr (SD) } & 44.6(13.0) & 43.8(13.9) \\ \text { Donor sex (M/F) } & 83 / 60 & 74 / 68 \\ \text { Living donor } & 3(2.1) & 4(2.8) \\ \text { \% Mean PRA (SD) } & 2.1(7.2) & 1.6(6.5) \\ \text { Mean HLA incompatibilities (SD) } & 3.5(1.2) & 3.4(1.2) \\ \text { Cold ischemia time, hr (SD) } & 14.5(4.7) & 13.8(4.9) \\ \text { Recipient CMV }{ }^{-} / \text {Donor } & 12(8.4) & 11(7.7) \\ \quad \text { CMV } & \end{array}$

TX, transplantation; HLA, human leukocyte antigen; CMV, cytomegalovirus.

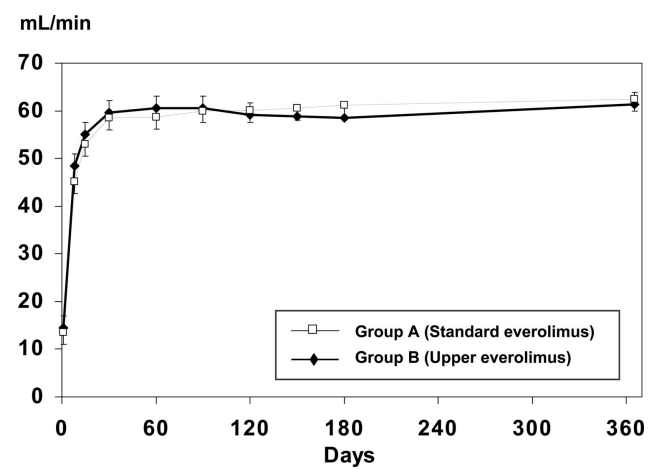

FIGURE 2. Creatinine clearance. Mean (SE) creatinine clearance, calculated according Cockcroft and Gault formula, in patients with functioning grafts. Open square: group A (standard everolimus). Black diamonds: group B (upper everolimus). There were no significant differences.

\section{Post Hoc Analysis}

The treatment compliant population comprised 107 patients in group A and 57 patients in group B. The 6-month mean values of $\mathrm{CrCl}$, using the LOCF approach were, respectively, $52.9 \pm 26.2$ and $58.5 \pm 23.2 \mathrm{~mL} / \mathrm{min}$ in groups $\mathrm{A}$ and $\mathrm{B}$, with a difference between groups of $5.5 \mathrm{~mL} / \mathrm{min}$ in favor of group $\mathrm{B}(P=\mathrm{NS})$. In the treatment compliant population, the probability of having a BPAR within the first 6 months were $14.9 \%$ in group A and $12.6 \%$ in group B $(P=\mathrm{NS})$.
TABLE 2. Primary and secondary efficacy measures at $6 \mathrm{mo}$

\begin{tabular}{lccc} 
& $\begin{array}{c}\text { Standard } \\
\text { everolimus, } \\
\text { group A } \\
(\mathbf{N = 1 4 3 )}\end{array}$ & $\begin{array}{c}\text { Upper } \\
\text { everolimus, } \\
\text { group B } \\
(\mathbf{N = 1 4 2})\end{array}$ & $\begin{array}{c}\text { Overall } \\
(\mathbf{N = 2 8 5})\end{array}$ \\
\hline Patient survival $^{a}$ & 98.6 & 98.6 & 98.6 \\
$\begin{array}{l}\text { Graft survival } \\
(\text { death censored })^{a}\end{array}$ & 90.2 & $97.9^{b}$ & 94.1 \\
$\begin{array}{c}\text { Graft survival } \\
(\text { not death censored })^{a}\end{array}$ & 88.8 & $96.5^{b}$ & 92.6 \\
$\begin{array}{l}\text { BPAR }^{a} \\
\text { Treated acute rejection/ } \\
\text { BPAR }^{c}\end{array}$ & 14.7 & 11.9 & 13.3 \\
$\begin{array}{c}\text { Steroid resistant acute } \\
\text { rejection }\end{array}$ & 60.6 & 16.4 & 17.5 \\
\hline
\end{tabular}

${ }^{a}$ Probability of event.

${ }^{b} P<0.05$

${ }^{c}$ Treated ARs were defined as a serum creatinine increase $\geq 30 \%$ over the baseline, in absence of renal biopsy, not explained by other medical or surgical complications, that improved after administration of MPP.

${ }^{d}$ Actual proportion of patients with steroid-resistant AR. AR was classified as steroid-resistant when serum creatinine levels did not improve 4 to $5 \mathrm{~d}$ after the administration of intravenous MPP. Any suspected rejection was carefully investigated to exclude vascular occlusion, urinary obstruction, or laboratory errors in serum creatinine determination. Severity of acute rejection is reported according Banff criteria ' 97.

BPAR, biopsy-proven acute rejection; AR, acute rejection; MPP, methylprednisolone pulses.

\section{Secondary Endpoints}

Treated AR (either confirmed or not by graft biopsy) occurred in 29 patients (20.3\%) of group A and in 23 patients of group B $(16.2 \% ; P=\mathrm{NS})$ in the first 6 months and in one further patient of group A versus 6 patients of group B $(P=0.06)$ after month 6 . The cumulative number of patients with rejection within month 12 was $30(21 \%)$ in group A and $29(20.4 \%)$ in group B. Steroid resistant AR occurred in nine patients of group A $(6.3 \%)$ and in three of group B $(2.1 \%$; $P=0.08)$. There was a trend for less severe BPAR in group B: in fact, there were 11 episodes of grade II to III BPAR in group A as opposed to four in group B $(P=0.065, N S)$. Table 2 reports the 6-month estimates (Kaplan and Meier) of having a treated acute rejection or a steroid resistant acute rejection in the two groups. Ten patients of group A received a second transplant: two lost their allograft and two had a reversible, steroid-resistant AR. None of the five patients of group B who received a second transplant, lost their allograft, or had a steroid resistant AR. Of the seven group A patients with $20 \%$ to $50 \%$ anti-HLA antibodies, two lost their allograft and two had a reversible, steroid resistant AR. In group B, of the six patients with preformed anti-HLA antibodies, one lost the graft because of rejection and another patient had a reversible, steroid resistant AR. Overall, 22 study patients (7.8\%) had one or more immunological risk factors. In this subgroup there were 4 graft losses (18.2\%); in the remaining patients without immunological risks, the overall graft loss rate was $5.0 \%(13 / 258)$.

DGF occurred in 44 patients (30.8\%) in group $\mathrm{A}$ and 33 $(23.2 \%)$ in group $B(P=\mathrm{NS})$. Excluding four patients in group A who received nonviable kidneys, the mean post- 
FIGURE 3. Mean blood levels of immunosuppressive drugs. Group A (standard everolimus, open squares); group B (upper everolimus, black diamonds). Vertical bars represent the interquartile ranges $(25 \%-75 \%)$.

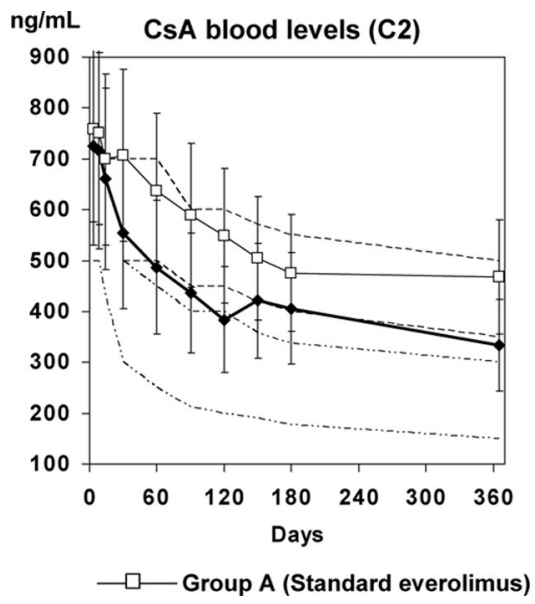

$\mathrm{ng} / \mathrm{mL}$ Everolimus blood levels (CO)

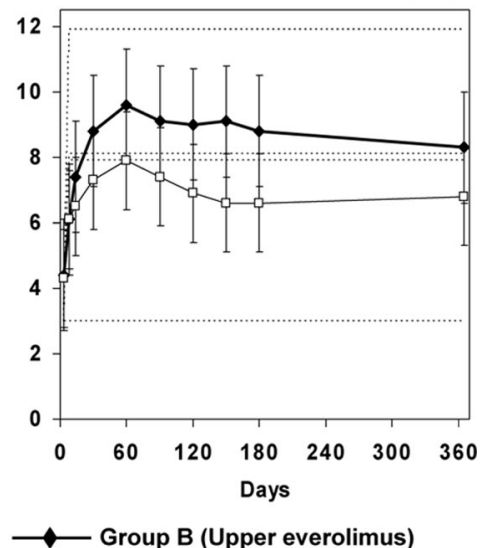

transplant time on dialysis was $9.3 \pm 13.1$ days ( 1 to 68 ) in group A and 7.2 \pm 7.3 days ( 1 to 27$)$ in group $B(P=0.4$, NS).

The mean serum creatinine values at 6 and 12 months were, respectively, $1.56 \pm 0.52$ and $1.51 \pm 0.55 \mathrm{mg} / \mathrm{dL}$ in group $A$ and $1.63 \pm 0.59$ and $1.55 \pm 0.62$ in group $B(P=N S)$.

\section{Graft Loss and Deaths}

In group $\mathrm{A}$, graft never recovered any function in four patients $(2.9 \%)$. Ten other patients $(7 \%)$ lost their graft, two because of renal thrombosis after recovery of graft function, two because of irreversible rejection, and one because of kidney rupture; four other patients had an AR superimposed to DGF and one was nephrectomized because of a donor-derived mycotic aneurysm. Three patients $(2.1 \%)$ lost their graft in group $\mathrm{B}$, respectively, because of renal vein thrombosis, renal infarction, and kidney rupture/DGF. No graft failure occurred after the sixth month.

Two patients died (1.4\%) in group A, one of myocardial infarction and one of pulmonary edema. Two patients died $(1.4 \%)$ in group B, respectively, from myocardial infarction and ruptured arterial mycotic aneurysm of donor origin. All deaths occurred within the sixth month.

According to ITT analysis, the 6- and 12-month deathcensored graft survival was $90.2 \%$ in group A and $97.9 \%$ in group $\mathrm{B}(P=0.007)$. Excluding the four patients who received a nonviable kidney, the 6-month death-censored graft survival in group A was $92.8 \%$.

\section{Immunosuppression}

The mean EVL dosage was $1.44 \pm 0.6 \mathrm{mg} /$ day in group $\mathrm{A}$ and $2.23 \pm 1.0 \mathrm{mg} / \mathrm{day}$ in group $\mathrm{B}$ at 6 months; it was $1.45 \pm 0.6$ and $2.31 \pm 1.0 \mathrm{mg} / \mathrm{day}$ at 12 months. The blood levels of EVL tended to remain toward the higher limit of the scheduled range in group A and toward the lower limit in group B (Fig. 3).

The mean dosage of CsA at 6 months was $1.92 \pm 0.5$ $\mathrm{mg} / \mathrm{kg}$ per day in group A versus $1.56 \pm 0.6 \mathrm{mg} / \mathrm{kg}$ per day in group B; at 12 months, the mean dosages in groups $\mathrm{A}$ and $\mathrm{B}$ were, respectively, $1.74 \pm 0.5$ and $1.43 \pm 0.6 \mathrm{mg} / \mathrm{kg}$ per day. The mean CsA C2 levels were within the scheduled range in group A but exceeded the upper target limit in group B, being $405.7 \pm 209$ and $332.7 \pm 152 \mathrm{ng} / \mathrm{mL}$ at 6 and 12 months, respectively (Fig. 3 ).
The mean prednisone daily dosages were $7.32 \pm 4.8 \mathrm{mg}$ in group $A$ and $6.2 \pm 3.2 \mathrm{mg}$ in group $B$ at 6 months and $5.09 \pm 1.8$ and 5.5 \pm 4.5 , respectively, at 12 -month $(P=\mathrm{NS})$.

\section{Center Effect}

A post hoc analysis showed that the graft loss rate by center ranged from $0 \%$ to $18.2 \%$, and it was $8.16 \%(8 / 98$ patients) in centers including less than 14 patients in the study, as compared with $4.8 \%$ (9/187 patients) in centers including 14 patients or more. There were no significant differences between centers about the rate of BPAR or mean $\mathrm{CrCl}$.

\section{Safety}

There were no differences between groups in the percentage of patients who experienced at least one AE, one SAEs or in the number of patients who discontinued study treatment due to AE (Tables 3-5). Although frequently reported as an AE, anemia was mainly found in the early posttransplant period and was reported as SAE in only $2.8 \%$ of the patients in group A and $2.1 \%$ in group B. Mean hemoglobin levels at 6 months were $12.6 \pm 1.5 \mathrm{~g} / \mathrm{dL}$ in group A versus $12.5 \pm 1.9 \mathrm{~g} / \mathrm{dL}$ in group B and tended to improve up to the twelfth month $(13.0 \pm 1.5$ vs. $12.8 \pm 1.6 \mathrm{~g} / \mathrm{dL})$, respectively. However, 23 patients $(16.1 \%)$ in group A and $33(23.2 \%)$ in group B were given erythropoietin as a maintenance therapy $(P=\mathrm{NS})$. Arthralgia and hypocalcemia were more frequent in group $B$, Urinary tract infections, dyslipidemia, pyrexia, peripheral edema, and lymphocele were other frequently reported AEs, without significant differences between groups. New onset diabetes after transplantation was diagnosed in $2.1 \%$ of patients in group A and $4.9 \%$ in group B (NS). Two patients in group B (1.4\%) and one patient in group A (0.7\%) developed nonmelanoma skin cancer. Infection was the most frequently reported SAE, followed by pyrexia (more frequent in group A) and lymphocele (more frequent in group B).

Overall, approximately $17 \%$ of enrolled patients stopped EVL treatment within month 6 due to AEs, mostly because of early events (nonimmunologic graft complications in group A [4.9\%] and graft dysfunction in group B $[2.8 \%])$. After the sixth month, no patient in group A versus 6 in group $B(P<0.05)$ had to interrupt EVL due to AEs (increased serum creatinine 2 , anemia 1 , edema 1 , mucositis 1 , proteinuria 1). One patient in group A (gum hyperpla- 
TABLE 3. Adverse events within 12 mo: listing of more frequent adverse events by system organ class and preferred term

\begin{tabular}{|c|c|c|}
\hline Adverse events (\%) & $\begin{array}{c}\text { Standard } \\
\text { everolimus, } \\
\text { group A } \\
(\mathrm{N}=143)\end{array}$ & $\begin{array}{c}\text { Upper } \\
\text { everolimus, } \\
\text { group B } \\
(\mathrm{N}=142)\end{array}$ \\
\hline Blood and lymphatic disorders & 51.8 & 59.9 \\
\hline Anemia & 48.3 & 56.3 \\
\hline Infections and infestations & 67.1 & 62.0 \\
\hline Urinary tract infection & 53.9 & 45.1 \\
\hline Metabolism and nutrition disorder & 86.1 & 91.6 \\
\hline Dyslipidemia & 36.4 & 45.1 \\
\hline Hyperuricemia & 19.6 & 19.1 \\
\hline Hypocalcemia $^{a}$ & 13.3 & 23.2 \\
\hline Hypercholesterolemia & 14.7 & 15.5 \\
\hline Hypokalemia & 19.6 & 15.5 \\
\hline General disorders & 51.1 & 48.6 \\
\hline Pyrexia & 30.1 & 26.1 \\
\hline Peripheral edema & 22.4 & 23.2 \\
\hline $\begin{array}{l}\text { Musculoskeletal and connective } \\
\text { tissue disorders }\end{array}$ & 15.4 & 16.2 \\
\hline Arthralgia $^{a}$ & 2.8 & 8.5 \\
\hline Vascular disorders & 42.0 & 45.8 \\
\hline Hypertension & 19.6 & 21.1 \\
\hline Lymphocele & 15.4 & 21.1 \\
\hline Transplant complications & 25.2 & 16.2 \\
\hline Renal dysfunction & 11.2 & 17.6 \\
\hline Gastrointestinal disorders & 34.3 & 40.1 \\
\hline Diarrhea & 11.2 & 9.9 \\
\hline Constipation & 7.7 & 12.7 \\
\hline New onset diabetes & 2.1 & 4.9 \\
\hline
\end{tabular}

${ }^{a}$ Hypocalcemia $(P<0.05)$ and arthralgia $(P<0.05)$ were more frequently observed in group B.

sia) and three patients in group B (abdominal abscess, pancreatitis, and urinary tract infection, respectively) also changed immunosuppression. Table 5 reports the AEs requiring study drug discontinuation within month 12 .

\section{Infections}

The overall incidence of serious infections (requiring hospitalization) was low and similar in the two groups (10.5\% in group A and $14.5 \%$ in group B, Table 4).

\section{Blood Pressure}

Before transplantation, $81.1 \%$ of patients in group A and $88.7 \%$ in group B were on antihypertensive treatments, that were maintained almost unchanged after transplantation. There was no difference between groups $\mathrm{A}$ and $\mathrm{B}$ in the mean number of antihypertensive medication assumed during study (2.6 vs. 2.8). In both groups, systolic blood pressure at 6 months was significantly decreased in comparison with pretransplant values (from $136 \pm 21$ to $131 \pm 15 \mathrm{~mm} \mathrm{Hg}$ in group A, from $140 \pm 21$ to $134 \pm 17 \mathrm{~mm} \mathrm{Hg}$ in group B, $P<0.05$ for both). Diastolic blood pressure was $79.1 \pm 9.0 \mathrm{~mm}$ $\mathrm{Hg}$ in group A and $80.1 \pm 9.1 \mathrm{~mm} \mathrm{Hg}$ in group B at 6 months
TABLE 4. Adverse events within 12 mo: listing of serious adverse events and cancer

\begin{tabular}{lcc} 
Serious adverse events (\%) & $\begin{array}{c}\text { Standard } \\
\text { everolimus, } \\
\text { group A } \\
(\mathbf{N = 1 4 3 )}\end{array}$ & $\begin{array}{c}\text { Upper } \\
\text { everolimus, } \\
\text { group B } \\
\text { (N=142) }\end{array}$ \\
\hline Any event & 52.5 & 50.1 \\
Blood and lymphatic disorders & 4.9 & 2.8 \\
Anemia & 3.5 & 2.1 \\
Cardiac disorders & 2.8 & 4.9 \\
Infections and infestations & 10.5 & 14.1 \\
Urinary tract infection & 1.4 & 3.5 \\
CMV infection & 1.4 & 2.1 \\
Pneumonia & 1.4 & 2.1 \\
Metabolism and nutrition disorder & 0.7 & 2.1 \\
Diabetes & - & 0.7 \\
General disorders & 11.2 & 7.8 \\
Pyrexia & 9.1 & 7.0 \\
Respiratory disorders & 4.9 & 2.1 \\
Pneumonitis & 3.5 & 1.4 \\
Vascular disorders & 9.8 & 14.1 \\
Aneurism & 2.8 & 0 \\
Deep vein thrombosis & 1.4 & 2.8 \\
Lymphocele & 3.5 & 8.5 \\
Renal and urinary disorders & 14.0 & 9.9 \\
Renal impairment & 2.1 & 1.4 \\
Ureteric stenosis & 3.5 & 1.4 \\
Gastrointestinal disorders & 4.9 & 7.8 \\
Cancer & 1.4 & 1.4 \\
Basal cell carcinoma & 0 & 1.4 \\
Epithelioma & 0.7 & 0 \\
Neoplasm, unspecified & 0.7 & 0 \\
\hline & & \\
\hline
\end{tabular}

The mean levels of blood pressure at 12 months were $131 \pm 16$ $\mathrm{mm} \mathrm{Hg}$ or $79 \pm 9.4 \mathrm{~mm} \mathrm{Hg}$ in group A versus $134 \pm 18 \mathrm{~mm} \mathrm{Hg}$ and $81 \pm 11 \mathrm{~mm} \mathrm{Hg}$ in group B.

\section{Laboratory Examination}

Mean plasma cholesterol levels at transplantation were $171 \pm 50 \mathrm{mg} / \mathrm{dL}$ in group A and $169 \pm 43$ in group B. Cholesterol mean values were $234.9 \pm 48 \mathrm{mg} / \mathrm{dL}$ in both groups at 6 months and $231.4 \pm 40.1$ versus $234.4 \pm 45.9$ $\mathrm{mg} / \mathrm{dL}$ at 12 months. Triglycerides levels at transplantation were $154.5 \pm 98$ versus $149.5 \pm 95 \mathrm{mg} / \mathrm{dL}$ in groups $\mathrm{A}$ and $\mathrm{B}$, $220.4 \pm 118$ versus $236.0 \pm 131 \mathrm{mg} / \mathrm{dL}$ at 6 months, and $195.4 \pm 93$ versus $224.0 \pm 115 \mathrm{mg} / \mathrm{dL}$ at 12 months. Statins were administered in $45.1 \%$ and $60.6 \%$ of patients in groups A and B, respectively.

There were only small changes in the mean values of leukocytes and platelets during study (data not shown).

\section{Drug Blood Levels/BPAR Relationship}

Most ARs occurred within the first 3 months after transplantation. The mean C0 EVL and C2 CsA blood levels at day 7, month 1 , and month 3 were, respectively, $6.1,8.1$, and $8.2 \mathrm{ng} / \mathrm{mL}$ and 734,631 , and $511 \mathrm{ng} / \mathrm{mL}$. Overall, the incidence of BPAR in 
TABLE 5. Adverse events causing study/study drug discontinuation (\%) within 12 mo

\begin{tabular}{|c|c|c|}
\hline & $\begin{array}{c}\text { Standard } \\
\text { everolimus, } \\
\text { group A } \\
(\mathbf{N}=143)\end{array}$ & $\begin{array}{c}\text { Upper } \\
\text { everolimus, } \\
\text { group B } \\
(\mathrm{N}=142)\end{array}$ \\
\hline Any event & 17.5 & 23.2 \\
\hline Anemia & 0.7 & 0.7 \\
\hline Hemolytic uremic syndrome & 0.7 & 0 \\
\hline Leukopenia & 2.1 & 1.4 \\
\hline Thrombocytopenia & 0.7 & 1.4 \\
\hline Acute myocardial infarction & 0.7 & 0.7 \\
\hline Cardiac arrest & 0 & 0.7 \\
\hline Cardiomyopathy & 0.7 & 0 \\
\hline Apthous stomatitis & 0 & 2.1 \\
\hline Mucositis & 0 & 0.7 \\
\hline Gingival hyperplasia & 0.7 & 0 \\
\hline Pancreatitis & 0 & 0.7 \\
\hline Peripheral edema & 0.7 & 1.4 \\
\hline Kidney transplant rejection & 5.6 & 4.2 \\
\hline Abdominal abscess & 0 & 0.7 \\
\hline CMV infection & 0.7 & 0 \\
\hline Urinary tract infection & 0 & 0.7 \\
\hline $\begin{array}{l}\text { Non immunological graft } \\
\text { complications }\end{array}$ & 4.9 & 1.4 \\
\hline Increased serum creatinine & 0.7 & 2.8 \\
\hline Arthralgia & 0 & 2.8 \\
\hline Arthropathy & 0 & 0.7 \\
\hline Osteonecrosis & 0 & 0.7 \\
\hline Tremor & 0 & 0.7 \\
\hline Renal impairment & 0 & 1.4 \\
\hline Pneumonitis & 0 & 0.7 \\
\hline Pulmonary edema & 0.7 & 0 \\
\hline Aneurysm & 0.7 & 0 \\
\hline Deep vein thrombosis & 0 & 0.7 \\
\hline
\end{tabular}

Adverse events (percentage of patients with $\mathrm{AE}$ ) are listed independently from the relationship with study drug, including SAE, cancer and adverse events that required discontinuation of study or study treatment.

the first 3 months was 0.11 (Kaplan and Meier). The risk of BPAR in the first 3 months after transplantation was significantly correlated with the presence of low EVL C0 levels $(P<0.05)$ but not with CsA C2 levels $(P=0.131, \mathrm{NS})$.

\section{DISCUSSION}

A major challenge in renal transplantation is the avoidance of calcineurin inhibitors (CNIs). A few controlled trials evaluated the use of CNI-free regimens (11-14), but increased rates of AEs (13) or rejection (14) were reported. Some investigators warned that CNI should not be abandoned $(15,16)$, but there is no doubt that a minimization in their dosage is desirable to reduce the CNI-related morbidity. In this regard, the synergistic interaction between CsA and EVL can provide the rationale to reduce the doses of CsA (17). The efficacy of EVL combined with low doses of CsA in renal transplantation has been confirmed $(4,5)$, but the optimal dosage of CsA and EVL when given in combination is still unknown. Aim of this trial was to elucidate whether there was a difference between a regimen based on the association of low-dose CsA with standard exposure to EVL or a regimen based on even lower doses of CsA combined with higher exposure to EVL.

The cumulative mortality was low (1.4\%) and was mainly caused by cardiac events that occurred in patients with preexisting risk factors. The graft survival was significantly better in group B, with only three failures, than in group A (14 graft losses). Vascular thrombosis or kidney rupture was the cause of graft loss in 6 of 281 patients $(2.1 \%)$, a rate compatible with the $2 \%$ to $7 \%$ reported in adult renal transplant (18). The cumulative graft survival censored for death, including the four patients who received a graft that never functioned (94.1\%), was similar to the graft survival (91.9-96.4) reported in RCT recently published $(14,19)$, despite the relevant number of patients with immunological risk factors $(7.8 \%)$ and the high proportion of deceased donors (97\%) in our series.

It is interesting to note that in our study, the rate of graft loss seemed to be larger in centers that included a lower number of patients. This is in agreement with the observation that centers with low volume kidney transplants reports a higher incidence of graft loss when compared with high volume centers (20).

The noninferiority in the BPAR rate of group B versus group A was achieved. However, no difference was seen in the primary outcome measure, namely $\mathrm{CrCl}$. At 6 and 12 months, the mean $\mathrm{CrCl}$ was similar in the two groups, ranging around $60 \mathrm{~mL} / \mathrm{min}$. In the treatment compliant population, a difference of $5 \mathrm{~mL} / \mathrm{min}$ in $\mathrm{CrCl}$ was observed in favor of group B, but this difference was not significant, possibly because of the reduced number of patients in this analysis. In group $\mathrm{A}, \mathrm{a}$ higher number of patients showed DGF, and the median duration of DGF was longer, but the differences with group B were not significant.

As expected, the cumulative proportion of treated AR within 6 months $(17.5 \%)$ was higher than that of BPAR (13.3\%). This difference of $4.2 \%$ is comparable with differences ranging from $4.5 \%$ to $6 \%$ observed in other multicenter RCT $(14,19,21)$. No significant difference was seen in the incidence of treated or steroid-resistant AR between groups. However, there were more grade II or III rejections in group A and more patients in group A proved to be steroid resistant and had to be treated with antilymphocyte antibodies. No patient in group $\mathrm{B}$ lost the graft with a concomitant diagnosis of AR in comparison with six in group $\mathrm{A}(P<0.05)$.

Anemia was frequently reported, mainly in the first period after transplant, but the mean levels of hemoglobin approached the normal values at 6 and 12 months after transplantation, although approximately $20 \%$ of the patients of either group was given erythropoietin. Anemia was reported as serious in less than $3 \%$ of patients in both groups. Treatment with EVL may be associated with hyperlipemia and myelosuppression $(2,4$, 5). Also in our study, cholesterol and triglyceride levels were increased, although the mean values were at borderline levels according to National Cholesterol Education Program Guidelines (22). However, approximately $80 \%$ of the patients took serum lipids modifying agents, mainly statins. The overall incidence of De novo hyperglycemia or diabetes was com- 
parable with that observed in other trials using the EVL-CsA combination (2-4).

The mean levels of systolic and diastolic blood pressure were within the normal range at 6 and 12 months, although most patients had to take antihypertensive drugs. It is possible that the low doses of CsA and steroids used in this trial favored a better control of blood pressure.

The overall incidence of lymphocele was lower than 20\%, an incidence that is comparable with that observed in transplant patients not given mammalian target of rapamycin inhibitors $(14,23)$ and with the $7.2 \%$ to $18.6 \%$ reported in former EVL trials $(2,4,5,24,25)$. There was a trend for more frequent and more serious lymphocele in group B.

A limitation of this study is represented by the partial overlapping of CsA blood levels in the two groups. Most participants used doses of CsA higher than scheduled in group B, so that the differences in blood CsA C2 levels, although statistically significant, were lower than expected. This issue is frequent in studies with targeted blood levels of drugs, as recently reported in a large multicenter RCT (19). The overlapping of CsA blood levels between the two groups possibly contributed to the lack of significance in the difference of $\mathrm{CrCl}$ between groups, the primary outcome measure.

Despite CsA blood levels in group B were not lowered as expected, the mean C2 blood levels at 12 months in this group are the lowest levels of CsA obtained in a large, RCT. In this group, EVL blood levels were within the target ranges up to month 6, although close to the lower limit, and then showed a decreasing trend up to the twelfth month. We observed a more frequent EVL discontinuation in group B after the sixth month. Our data seem to suggest that EVL blood levels should be reduced after the sixth month, although the higher than planned CsA blood levels might have contributed to the higher discontinuation rate after the sixth month.

In summary, this multicenter RCT conducted in a large number of centers in Italy under standard clinical settings failed to show that higher EVL blood levels in combination with very low exposure to $\mathrm{CsA}$ further improve $\mathrm{CrCl} 6$ months after kidney transplantation; however, the combination of upper level EVL with very low-exposure to CsA showed a significantly better 1-year graft survival, low rate of BPAR, a good control of CNI related AEs, such as hypertension, diabetes, gum hyperplasia and hypertrichosis, and a low rate of serious infections.

\section{ACKNOWLEDGIMNTS}

The authors thank Roberto Ferrara for the great expertise and contribution in reviewing the protocol and the coinvestigators and study coordinators at each participating center.

The following centers in Italy contributed to patient enrollment and treatment and to data collection: Renal Transplant Unit, Careggi University Hospital, Firenze (M. Salvadori, E. Bertoni); Renal Transplant Unit, S. Orsola Malpighi University Hospital, Bologna (M.P. Scolari, S. Stefoni); Department of Surgery, Catholic University Hospital, Roma (F. Citterio); Surgery Division, Policlinico University Hospital, Padova (P. Rigotti); Renal Transplant Unit, SS. Annunziata Hospital, Sassari (M. Cossu); Renal transplant Unit, IRCCS S. Matteo University Hospital, Pavia (A. Dal Canton); Division of Surgery and Renal Transplant Unit, S. Eugenio University Hospital (G. Tisone), Roma; Renal Transplant Unit, Policlinico University Hospital, Mod- ena (A. Albertazzi); Renal Transplant Unit, Civile S. Salvatore Hospital, l'Aquila (A. Famulari, F. Pisani); Renal Transplant Unit, S. Maria della Misericordia Hospital, Perugia (G. Gubbiotti); Renal Transplant Unit, G. Brotzu Hospital, Cagliari (G. Piredda, P. Altieri); Renal Transplant Unit, Niguarda Cà Granda Hospital, Milano (G. Busnach, E. Minetti); Renal Transplant Unit, S. Bortolo Hospital, Vicenza (S. Chiaramonte, $V$. Goepel); Nephrology and Renal Transplant Unit, IRCCS De Marchi and Policlinico Foundation, Milano (P. Messa, L. Berardinelli); Clinica Chirurgica II, Umberto I University Hospital, Roma (P. Berloco, Mennini); Renal Transplant Unit, S.Maria della Misericordia University Hospital, Udine (D. Montanaro, Tulissi); Vascular Surgery and Transplant Unit, Policlinico Hospital, Catania (P.F. Veroux); Renal Transplant Unit, University Hospital Federico II, Napoli (S. Federico).

\section{REFERENCES}

1. Kovarik JM, Kaplan B, Silva HT, et al. Pharmacokinetics of an everolimuscyclosporine immunosuppressive regimen over the first 6 months after kidney transplantation. Am J Transplant 2003; 3: 606.

2. Vitko S, Margreiter R, Weimar W, et al. Three-year efficacy and safety results from a study of everolimus versus mycophenolate mofetil in de novo renal transplant patients. Am J Transplant 2005; 5: 2521.

3. Lorber MI, Mulgaonkar S, Butt KM, et al. Everolimus versus mycophenolate mofetil in the prevention of rejection in de novo renal transplant recipients: A 3-year randomized, multicenter, phase III study. Transplantation 2005; 80: 244.

4. Nashan B, Curtis J, Ponticelli C, et al; 156 Study Group. Everolimus and reduced-exposure cyclosporine in de novo renal-transplant recipients: A three-year phase II, randomized, multicenter, open-label study. Transplantation 2004; 78: 1332.

5. Tedesco-Silva H Jr, Vitko S, Pascual J, et al; 2306 and 2307 study groups. 12-month safety and efficacy of everolimus with reduced exposure cyclosporine in de novo renal transplant recipients. Transpl Int 2007; 20: 27.

6. Cockcroft DW, Gault MH. Prediction of creatinine clearance from serum creatinine. Nephron 1976; 16: 31.

7. Racusen LC, Solez K, Colvin RB, et al. The Banff 97 working classification of renal allograft pathology. Kidney Int 1999; 55: 713.

8. Nankivell BJ, Gruenewald SM, Allen RD, et al. Predicting glomerular filtration rate after kidney transplantation. Transplantation 1995; 59: 1683.

9. Stablein DM, Carter WH. Survival analysis of drug combinations using a hazard model with time-dependent covariates. Biometrics 1980; 36: 537.

10. Delucchi KL. Methods for the analysis of binary outcome results in the presence of missing data. J Consult Clin Psychol 1994; 62: 569.

11. Larson TS, Dean PG, Stegall MD, et al. Complete avoidance of calcineurin inhibitors in renal transplantation: A randomized trial comparing sirolimus and tacrolimus. Am J Transplant 2006; 6: 514.

12. Flechner SM, Goldfarb D, Solez K, et al. Kidney transplantation with sirolimus and mycophenolate mofetil-based immunosuppression: 5 -year results of a randomized prospective trial compared to calcineurin inhibitor drugs. Transplantation 2007; 83: 883.

13. Buchler M, Caillard S, Barbier S, et al; SPIESSER Group. Sirolimus versus cyclosporine in kidney recipients receiving thymoglobulin, mycophenolate mofetil, and a 6-month course of steroids. Am J Transplant 2007; 7: 2522

14. Ekberg H, Grinyo J, Nashan B, et al. Cyclosporine sparing with mycophenolate mofetil, daclizumab and corticosteroids in renal allograft recipients: The CAESAR Study. Am J Transplant 2007; 7: 560.

15. Ponticelli C. Calcineurin-inhibitors in renal transplantation. Too precious to be abandoned. Nephrol Dial Transplant 2000; 15: 1307.

16. Meier-Kriesche HU, Hricik DE. Are we ready to give up on calcineurin inhibitors? Am J Transplant 2006; 6: 445.

17. Schuurman HJ, Cotton S, Fuchs S, et al. SDZ RAD, a new rapamycin derivative: Synergism with cyclosporine. Transplantation 1997; 64: 32.

18. Irish A. Renal allograft thrombosis: Can thrombophilia explain the inexplicable. Nephrol Dial Transplant 1999; 14: 2297. 
19. Ekberg H, Tedesco-Silva H, Demirbas A, et al. Reduced exposure to calcineurin inhibitors in renal transplantation. N Engl J Med 2007; 357: 2562.

20. Axelrod DA, Guidinger MK, McCullough KP, et al. Association of center volume with outcome after liver and kidney transplantation. Am J Transplant 2004; 4: 920.

21. Vincenti F, Friman S, Scheuermann E, et al. Results of an international, randomized trial comparing glucose metabolism disorders and outcome with cyclosporine versus tacrolimus. Am J Transplant 2007; 7: 1506.

22. Expert panel on detection, evaluation and treatment of high blood cholesterol in adults. Executive summary of the third report of the National Cholesterol Education Program (NCEP) Expert Panel on de- tection, evaluation, and treatment of high blood cholesterol in adults (Adult Treatment Panel III). JAMA 2008; 285: 2486.

23. Goel M, Flechner SM, Zhou L, et al. The influence of various maintenance immunosuppressive drugs on lymphocele formation and treatment after kidney transplantation. J Urol 2004; 171: 1788.

24. Montagnino G, Sandrini S, Iorio B, et al. A randomized exploratory trial of steroid avoidance in renal transplant patients treated with everolimus and low-dose cyclosporine. Nephrol Dial Transplant 2008; 23: 707.

25. Lorber MI, Ponticelli C, Whelchel J, et al. Therapeutic drug monitoring for everolimus in kidney transplantation using 12-month exposure, efficacy, and safety data. Clin Transplant 2005; 19: 145. 